\title{
Geist, Buchstabe und Buchstäblichkeit - Schleiermacher und seine Vorgänger
}

In:

Geist und Buchstabe : Interpretations- und Transformationsprozesse innerhalb des Christentums ; Festschrift für Günter Meckenstock zum 65. Geburtstag ISBN: 978-3-11-031116-7. - Berlin: De Gruyter, 2013

S. $105-129$ 


\title{
Geist und Buchstabe
}

\section{Interpretations- und Transformationsprozesse innerhalb des Christentums}

Festschrift für Günter Meckenstock zum 65. Geburtstag

\author{
Herausgegeben von \\ Michael Pietsch und Dirk Schmid
}

De Gruyter

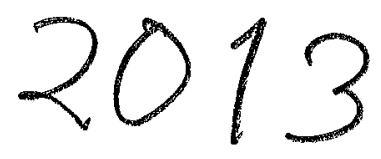




\title{
Geist, Buchstabe und Buchstäblichkeit - Schleiermacher und seine Vorgänger
}

\author{
Simon Gerber
}

Geist und Buchstabe, Buchstabe und Geist - dieses begriffliche Gegensatzpaar geht auf die Briefe des Apostels Paulus zurück. Paulus schreibt, der wahre Jude und Befolger des Gesetzes sei nicht der, der das bloß äußerlich sichtbar sei; entscheidend sei vielmehr das menschlicher Wahrnehmung und Beurteilung Verborgene, eine Beschneidung des Herzens und im Geist, nicht im Buchstaben (Röm 2,28f). Dann: Als solche, die mit Christus dem Gesetz und seinem Anspruch gestorben sind, sind die Christen dazu befreit Gott zu dienen im neuen Wesen des Geistes, nicht im alten Wesen des Buchstaben (Röm 7,6). Und schließlich schreibt Paulus den berühmten Satz: „Der Buchstabe tötet, aber der Geist macht lebendig" (2 Kor 3,6).

1.

Wo man Geist und Buchstaben einander zuordnet und voneinander unterscheidet, meint man im weitesten Sinne, dass Inneres und Äußeres zusammen gehören und doch einander nie ganz entsprechen können.

Als Geist und Buchstaben beschreibt man das Phänomen, dass der Gehalt und der Wortlaut eines Textes nicht zusammenfallen, dergestalt, dass etwa das, worauf ein geschriebenes Gesetz eigentlich zielt, umgangen werden kann, obwohl gegen seinen Wortlaut nicht verstoßen wird, oder dass der Buchstabe eines Gesetzes zum Instrument wird, Zweck und Geist der Gesetzgebung zu konterkarieren. Eine derartige Praxis wird in Mark 7,6-13; 10,2-12 den Pharisäern und Schriftgelehrten vorgeworfen. Umgekehrt schrieb Johann Gottlieb Fichte in der zweiten Einleitung in die Wissenschaftslehre, bei Immanuel Kants Vernunftkritik sei eine intellektuelle Anschauung dem Buchstaben nach zwar bekanntermaßen ausgeschlossen, aber wenn es mit der Erklärung nach dem Buchstaben nicht recht fort wolle, müsse man eben nach dem Geist erklären, also nach Idee, Zusammenhang und Absicht des Ganzen; eben das tue seine, Fichtes, Wissenschaftslehre, wenn sie feststelle, dass das Ich allerdings das 
Vermögen zu intellektueller Anschauung und zu absoluter Selbsttätigkeit habe. ${ }^{1}$ Kant freilich verwahrte sich gegen diesen Versuch eines selbsternannten Freundes, dem Geist seiner Philosophie gegenüber dem geschriebenen Wort aufzuhelfen: Seine Philosophie sei genau nach dem Buchstaben und nicht anders zu verstehen. ${ }^{2}$

Meist aber meint man, wenn man Geist und Buchstaben unterscheidet, mit dem Geist die schöpferische und erneuernde Kraft, die Inspiration, die sich in Werken der Kunst und der Welterkenntnis und in der Religion äußert und die auch in epochalen Umbrïchen der Geschichte erfahren wird. Der Buchstabe steht dann für alles das, worein sich der Geist nicht zwingen und zwängen lässt. Geist ist Originalität und spontane Begeisterung, er weht frei (Joh 3,8). Der Buchstabe ist der vergebliche Versuch, sich seiner zu bemächtigen, ihn in Formeln und Schemata einzufangen und festzulegen, ihn planbar zu machen; dadurch wird der Geist gerade ausgetrieben, es kommt nur ein geisttötendes Wesen heraus, eine fortdauernde Reproduktion der eigenen Geistlosigkeit. - Was der Geist hervorbringt, kann nur verstehen und beurteilen, wer selbst Geist hat. Die Äußerungen des Geistes lassen sich mit dem Buchstaben beschreiben, aber sie gehen nicht darin auf; der Geist sprengt die Formen, die er hervorbringt, immer wieder selbst auf.

In diesem Sinne veröffentlichte Fichte im Philosophischen Journal einen Aufsatz über Geist und Buchstaben in der Philosophie, der unvollendet blieb und weniger die Philosophie behandelt als die Ästhetik: Der Geist ist (in Anlehnung an Kant) die ,belebende Kraft an einem Kunstproducte“" , er ist der „Universalsinn der gesamten Menschheit“,

1 Johann Gottlieb Fichte, Versuch einer neuen Darstellung der Wissenschaftslehre, in: Philosophisches Journal 5 (1797), 1-49. 319-378; 6 (1797), 1-43; 7 (1797), 1-20, hier 5, 346-361 (in: Ders., Akademie-Ausgabe, Bd. I/4, hg. v. Reinhard Lauth/Hans Giewitzky unter Mitwirkung v. Richard Schottky, Stuttgart-Bad Cannstadt 1970, 224-233).

2 Immanuel Kant, Erklärung in Beziehung auf Fichtes Wissenschaftslehre, in: ALZ 14 (1799), Intelligenzblatt, Nr. 109 (28.8.), 876-878 (in: Ders., AkademieAusgabe, Bd. 12, 2. Aufl., Berlin/Leipzig 1922, 370 f).

3 Johann Gottlieb Fichte, Ueber Geist und Buchstab in der Philosophie, in: Philosophisches Journal 9 (1800), 199-232. 291-305, hier 205 (in: Ders., Akademie-Ausgabe, Bd. I/6, hg.v. Reinhard Lauth/Hans Giewitzky unter Mitwirkung v. Erich Fuchs/Kurt Hiller/Walter Schieche/Peter K. Schneider, Stuttgart-Bad Cannstadt 1981, 336). Vgl. Immanuel Kant, Critik der Urtheilskraft, 2. Aufl., Berlin 1793, $\$ 49$ (in: Ders., Akademie-Ausgabe, Bd. 5, Berlin 1908, 313 f); Ders., Anthropologie in pragmatischer Hinsicht, 2. Aufl., Kö- 
der den Künstler in der Stunde der Begeisterung ergreift ${ }^{4}$ und den dieser „,zum individuellen Charakter seines Geistes und seines Werkes macht ${ }^{\text {“5 }}$. So entwickelt der Künstler aus der Tiefe des eigenen Gemüts divinatorisch das, was allen gemeinsam ist, aber ohne ihn allen verborgen wäre. ${ }^{6}-$ Was sich dem Genie unverhüllt zeigt, das kleidet dieses, um es mitzuteilen, in feste Gestalten. ${ }^{7}$ Die innere Stimmung des Künstlers ist der Geist eines Kunstwerks; die äußere, feste Gestalt, in der sich der Künstler ausdrückt, ist der Körper oder Buchstabe des Kunstwerks. ${ }^{8}$

Friedrich Schleiermacher rekurriert im Zusammenhang mit Religion und Kirche häufig auf die Unterscheidung von Geist und Buchstaben. Er redet dann vom (toten, nicht tötenden) Buchstaben und von Buchstäblichkeit. Kennzeichen der Buchstäblichkeit als Haltung ist es, dass sie das genaue (eben „,buchstäbliche") Festhalten an bestimmten festgesetzten Lehrformeln und Ritualen für ein Mittel hält, um die wirksame Kraft einer Idee zu erhalten, oder auch für ein Kennzeichen, das die Treue zu einer Idee erweist.

$\mathrm{Zu}$ Beginn der ,Reden über die Religion' verteidigt der junge Schleiermacher die Religion gegen die Vorstellung ihrer Verächter, sie sei bloß ein System seltsamer metaphysischer und dogmatischer Sätze: Schon in der Philosophie seien die Schulen mit ihren Lehrsystemen Pflanzstätten des toten Buchstabens, nicht des lebendigen Geistes, den die Erfinder einst gehabt hätten; dieser Geist pflege vielmehr im Lehrbetrieb alsbald zu verdampfen. Die Religion aber sei ihrem Wesen nach noch weiter von allen Lehrsystemen entfernt als die Philosophie, und von den „Buch-

nigsberg 1800, $§ 71$ (in: Ders., Akademie-Ausgabe, Bd. 7, Berlin 1907, 246. 248).

4 Fichte, Ueber Geist (s.o. Anm. 3), 207 (in: Ders., Akademie-Ausgabe, Bd. I/6 [s.o. Anm. 3], 338).

5 Fichte, Ueber Geist (s. o. Anm. 3), 208 (in: Ders., Akademie-Ausgabe, Bd. I/6 [s.o. Anm. 3], 338).

6 Fichte, Ueber Geist (s.o. Anm. 3), 210 (in: Ders., Akademie-Ausgabe, Bd. I/6 [s.o. Anm. 3], 339 f).

7 Fichte, Ueber Geist (s. o. Anm. 3), 292 f (in: Ders., Akademie-Ausgabe, Bd. I/6 [s.o. Anm. 3], 354).

8 Fichte, Ueber Geist (s. o. Anm. 3), 296 (in: Ders., Akademie-Ausgabe, Bd. I/6 [s.o. Anm. 3], 356). 
stabentheologen", die meinten, das Heil der Welt und das Licht der Weisheit in dogmatischen Formulierungen und metaphysischen Beweisen zu finden, sollte man besser schweigen. ${ }^{9}$ Später heißt es, dass eben die Systematiker, die dem toten Buchstaben anhingen und die Religion so ihrem Wesen entfremdeten, auch immer diejenigen seien, die Ketzerverfolgungen und Religionskriege anzettelten. ${ }^{10}$

Toter Buchstabe seien aber nicht nur Gedanken- und Lehrsysteme, sondern auch heilige Schriften:

,Jede heilige Schrift ist nur ein Mausoleum der Religion ein Denkmal, daß ein großer Geist da war, der nicht mehr da ist; denn wenn er noch lebte und wirkte, wie würde er einen so großen Werth auf den todten Buchstaben legen, der nur ein schwacher Abdruk von ihm sein kann?"11

Die Pädagogen freilich, gegen die sich die dritte Rede richtet, sind in ihrem Wüten gegen alles zweckfrei Schöne, was sich ihrem Nützlichkeitsdenken und Moralismus entzieht, so rabiat, dass sie nach dem Geist auch noch den Buchstaben ausmerzen. ${ }^{12}$ - Für die Darstellung und Mitteilung religiöser Gedanken und Gefühle sei die schriftliche Form unangemessen und allenfalls ein Notbehelf; die Lebendigkeit des ursprünglich Darstellenden werde auf diese Weise nicht mitgeteilt. Erst wenn ein unmittelbares Einwirken nicht mehr möglich sei, verberge sich das religiöse Leben im toten Buchstaben. ${ }^{13}$ In dieser toten Hülle des Buchstabens lebe aber der Geist der Religion fort, bereit, aus der Erstarrung in neuer Gestalt zu neuer Lebendigkeit zu erwachen. ${ }^{14}$

9 [Friedrich Daniel Ernst Schleiermacher,] Über die Religion, Berlin 1799, $28 \mathrm{f}$ (in: Ders., Kritische Gesamtausgabe, hg.v. Hans-Joachim Birkner u.a., Bd. I/2, hg. von Günter Meckenstock, Berlin-West/New York 1984, 200 f).

10 [Schleiermacher,] Über die Religion' (s.o. Anm. 9), 64 (in: Ders., Kritische Gesamtausgabe, Bd. I/2 [s.o. Anm. 9], 217).

11 [Schleiermacher,] Über die Religion ${ }^{1}$ (s. o. Anm. 9), $121 \mathrm{f}$ (in: Ders., Kritische Gesamtausgabe, Bd. I/2 [s.o. Anm. 9], 242).

12 [Schleiermacher,] Über die Religion ${ }^{1}$ (s.o. Anm. 9), 152 (in: Ders., Kritische Gesamtausgabe, Bd. I/2 [s.o. Anm. 9], 255).

13 [Schleiermacher,] Über die Religion ${ }^{1}$ (s. o. Anm. 9), 179 f (in: Ders., Kritische Gesamtausgabe, Bd. I/2 [s.o. Anm. 9], 268).

14 [Schleiermacher,] Über die Religion ${ }^{1}$ (s.o. Anm. 9), 307 (in: Ders., Kritische Gesamtausgabe, Bd. I/2 [s.o. Anm. 9], 323 f). 
Der spätere Schleiermacher schreibt in den theologischen und kirchlichen Auseinandersetzungen seiner Zeit verschiedentlich von der seiner Meinung nach in der Kirche wieder aufgekommenen „Buchstäblichkeit". In der Vorrede zur dritten Auflage der Reden über die Religion schreibt Schleiermacher, die Zeiten hätten sich seit 1799 so geändert, dass man Reden jetzt nicht mehr an die Gebildeten unter den Religionsverächtern adressieren müsste, sondern

„an Frömmelnde und an Buchstabenknechte, an unwissend und lieblos verdammende Aber- und Uebergläubige “15.

Im kritischen Sendschreiben über den ersten Timotheusbrief von 1807 heißt es, wenn etliche nun klagten, es gingen ihnen viele Ermahnungsund Beweissprüche verloren, wenn der erste Timotheusbrief nach Schleiermachers These tatsächlich kein authentischer Brief des Apostels Paulus sei, dann sei das eine beklagenswerte „beschränkte Ansicht des heiligen Buchstabens"; schließlich müsse ein Satz, um im Sinne des Christentums zu sein, ja nicht unbedingt so dastehen. ${ }^{16}$

Vor Buchstäblichkeit und Knechtschaft des Buchstaben warnt Schleiermacher auch, wenn er dem widerrät, die Geistlichen beim Vollzug des Gottesdienstes auf den genauen Wortlaut der Agende festzulegen $^{17}$ oder die Theologen in Kirche und Universität bei der Lehre und Forschung auf den Buchstaben des Bekenntnisses zu verpflichten: Das widerspräche dem Geist der evangelischen Kirche im Allgemeinen und dem Schriftprinzip im Besonderen, das ja nicht vorsieht, dass das

15 Friedrich Daniel Ernst Schleiermacher, Ueber die Religion, 3. Aufl., Berlin 1821, XIV (in: Ders., Kritische Gesamtausgabe [s.o. Anm. 9], Bd. I/12, hg, v. Günter Meckenstock, Berlin/New York 1995, 10).

16 Friedrich Daniel Ernst Schleiermacher, Ueber den sogenannten ersten Brief des Paulos an den Timotheos, Berlin 1807, $8 \mathrm{f}$ (in: Ders., Kritische Gesamtausgabe [s.o. Anm. 9], Bd. I/5, hg.v. Hermann Patsch, Berlin/New York 1995, 158 f).

17 Vgl. Friedrich Daniel Ernst Schleiermacher, Erklärung des Unterzeichneten wegen der Agende (13.9.1825) (in: Ders., Kritische Gesamtausgabe [s.o. Anm. 9], Bd. 1/9, hg.v. Günter Meckenstock unter Mitwirkung v. HansFriedrich Traulsen, Berlin/New York 2000, 293); Ders., Vorstellung der unterschriebenen berlinischen Prediger (21.7.1825) (in: Ders., Kritische Gesamtausgabe [s.o. Antn. 9], Bd. I/9, 303); Ders., Memorandum der zwölf unterschriebenen Berliner Prediger (1.3.1826) (in: Ders., Kritische Gesamtausgabe [s.o. Anm. 9], Bd. I/9, 356 f). 
Forschen je zu einem definitiven Abschluss kommt. ${ }^{18}$ Wer einen Buchstaben aufstellt, danach urteilt und Verdammungsurteile fällt, an dem vollzieht sich das Urteil selbst, weil er selbst erstarrt und erstirbt. ${ }^{19}$ Das abschreckende Beispiel der Buchstäblichkeit sind ihm die in ihrem Dogma und Ritual in einer inzwischen unverständlichen Sprache erstarrten Ostkirchen:

„Nur an der äußerlichen Hïlle, Zeichen, erkennt man sie als christlich. [...]Die Gewalt des Buchstaben und der [dogmatischen] Streitigkeiten darüber ist als der einzige Grund davon anzusehn. Der Buchstabe tödtet, sagt der Apostel. Hier der schlagendste Beweis der Wahrheit dieses Ausspruchs. "20

Als einen Beitrag, das Gute in der Kirche zu fördern durch den Erweis, dass ihre Einheit und ihr Leben nicht im Buchstaben beruht, sondern im Geist, möchte Schleiermacher seine Novelle „Die Weihnachtsfeier" (in der das Gespräch eben nicht als Streit um Begriffe und um die allein richtige Formulierung der Wahrheit geführt wird) verstanden wissen, und ebenso seine Predigtreihe zum Jubiläum der Confessio Augustana. ${ }^{21}$

18 Vgl. Friedrich Daniel Ernst Schleiermacher, Ueber den eigenthümlichen Werth und das bindende Ansehen der symbolischen Bücher, in: Reformationsalmanach 2 (1819), 335-380, hier 346-362 (in: Ders., Kritische Gesamtausgabe [s.o. Anm. 9], Bd. I/10, hg. v. Hans-Friedrich Traulsen unter Mitwirkung v. Martin Ohst, Berlin/New York 1990, 125-134); Ders., An die Herren D. D. D. von Cölln und D. Schulz, in: ThStKr 4 (1831), 3-39, hier 24 f (in: Ders., Kritische Gesantausgabe [s.o. Anm. 9], Bd. I/10, 415).

19 Vgl. Friedrich Daniel Ernst Schleiermacher, Predigt 158 (10.10.1830) über Luk 6,37 (in: Ders., Predigten in Bezug auf die Feier der Uebergabe der Augsburgischen Confession [Predigten. Sechste Sammlung], Berlin 1831, $163 \mathrm{f}$; in: Ders., Sämmtliche Werke, Bd. II/2, Berlin 1834, 720 f).

20 Friedrich Daniel Ernst Schleiermacher, Kirchliche Statistik 1833/34, 5. Stunde (in: Ders., Kritische Gesamtausgabe [s.o. Anm. 9], Bd. II/16, hg.v. Simon Gerber, Berlin/New York 2005, 477).

21 Vgl. Friedrich Daniel Ernst Schleiermacher: Die Weihnachtsfeier, 2. Aufl., Berlin 1826, IV (in: Ders., Kritische Gesamtausgabe, Bd. I/5 [s.o. Anm. 16], 99 f); Ders. : Predigt 160 (7.11.1830) tuber Phil 1,6-11 (in: Ders., Predigten in Bezug auf die Feier [s.o. Anm. 19], 220; in: Ders., Sämmtliche Werke, Bd. II/2 [s.o. Anm. 19], 758). 
Geist, Buchstabe und Buchstäblichkeit - Schleiermacher und seine Vorgänger 111

4.

Der Schwerpunkt von Schleiermachers akademischer Lehrtätigkeit war bekanntlich die neutestamentliche Wissenschaft. Schleiermacher hat abgesehen von der Johannes-Offenbarung - über alle Bücher des Neuen Testaments Kollegien gehalten, dazu auch über die Hermeneutik, die Einleitung ins Neue Testament und das Leben Jesu. Die Ausarbeitung über 2 Kor 3,4-18, die wichtigste Stelle des Neuen Testaments über Geist und Buchstaben, soll im Folgenden ganz wiedergegeben werden. ${ }^{22}$

Schleiermacher hält den zweiten Korintherbrief gegen die damals schon aufgestellten Teilungshypothesen fuir einheitlich. ${ }^{23} \mathrm{Er}$ gliedert den Brief in Hauptteile, Unterabteilungen und Segmente. Der erste Hauptteil umfasst die Kapitel 1-7, darin die zweite Unterabteilung 2,13-5,10 (in einer Überarbeitung des Manuskripts hat Schleiermacher diese noch einmal geteilt und 4,7-5,10 als eigene Unterabteilung gerechnet), und in dieser bilden 3,4-18 die Segmente 4-6.

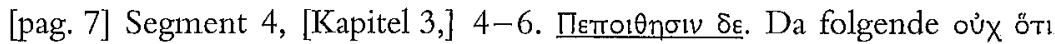
íavoí zeigt deutlich daß diese $\pi \varepsilon \pi 01 \theta$ noıs nicht auf das unmittelbar vorhergehende (als das Vertrauen auf die Wirksamkeit dieses geistigen Briefes) ${ }^{24}$ zurïkgeht sondern auf die $\varepsilon v \omega \delta ı \alpha$ auf die Gottgefälligkeit seines apostolischen

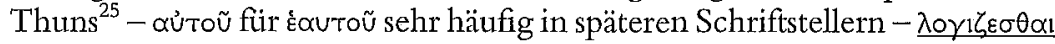
zusammendenken. Also auch auf den Prozeß der Gedankenverbindung im religiösen Gebiet erstrekt er das von Gott kommen (auf den also auch alles was dem Paulus in dieser Beziehung vorgeworfen werden könnte zurükfällt) - v 6. koi kann nur als auch gefaßt werden, bezeichnet aber einen Uebergang von dem specielen $\lambda_{0} \gamma / \zeta_{\varepsilon} \sigma \theta \propto l$ wobei eine Erinnerung an den Vorwurf wegen

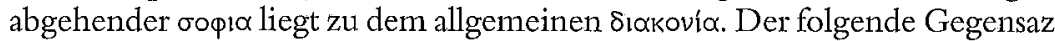

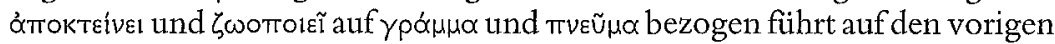

22 Das Manuskript liegt im Schleiermacher-Nachlass im Archiv der Berlin-Brandenburgischen Akademie der Wissenschaften und hat die Signatur SN 19. Schleiermachers exegetische Ausarbeitungen und seine Vorarbeiten für eine kritische Ausgabe der Paulusbriefe sind bisher noch nicht ediert. - Über den 2. Korintherbrief las Schleiermacher 1806, 1811, 1814/15, 1818 und 1830/31; vgl. Andreas Arndt/Wolfgang Virmond, Schleiermachers Briefwechsel (Verzeichnis) nebst einer Liste seiner Vorlesungen (SchlA 11), Berlin/New York 1992, 301. 306. 310. 313. 327 .

23 Vgl. Friedrich Daniel Erñst Schleiermacher, Zum 2. Korintherbrief (BerlinBrandenburgischen Akademie der Wissenschaften, Archiv, SchleiermacherNachlass SN 19, 1 f); Ders., Einleitung ins Neue Testament 1831/32, $\$ 44$ (in: Ders., Sämmtliche Werke, Bd. I/8, hg.v. Georg Wolde, Berlin 1845, 154 f).

24 Vgl. 2 Kor 3,2 f.

25 Vgl. 2 Kor 2,15. 



solche waren die nicht vom Judenthum lassen wollten und tro $\lambda \lambda$ or und tives Judaisirende. ${ }^{26}-\delta 1 \alpha \theta \eta \kappa \eta$ kann nicht eigentlich Bund übersezt werden son-

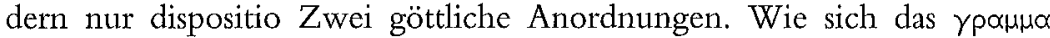

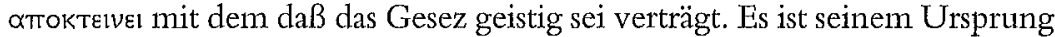
nach geistig weil es aus der Erkenntniß des Guten kommt aber da es sinnlich Motive zu Hülfe nimt treibt es nur die Sinnlichkeit. ${ }^{27}$ Eine solche göttliche Anordnung konnte daher nur vorübergehend sein

Segment 5 [Kapitel 3] v 7-11 Erweiterung dieser Vergleichung zur Vergleichung des Neuen Testaments mit Bezug auf den alttestamentlichen fastum. Die Behandlung desselben gehört in das Gebiet der allegoria. Hier war nun nicht die Voraussezung [pag. 8] daB der so behandelte Text ursprünglich die allegorische Bedeutung gehabt habe sondern nur die Absicht das was man sagen wollte an eine Stelle des Codex als ein bekanntes und heiliges anzuknïpfen und dadurch mit einem bestimmten Eindrukk ein-

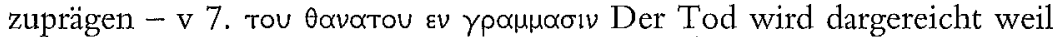

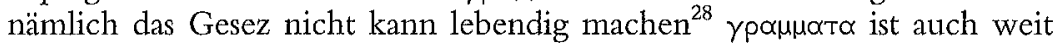
richtiger da es ganz zu dem Gegensaz Geist und Buchstabe gehört. Man kann

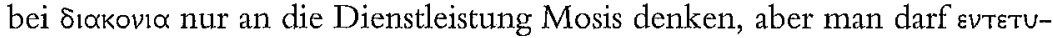
$\pi \omega \mu \varepsilon v \eta \lambda \lambda_{1} \theta$ oıs welches für die Vergleichung ganz überflüssig erscheint aber doch auf das vorige $\pi \lambda \alpha \xi \xi_{1} \lambda_{1} \theta_{l v \alpha}{ }_{15}^{29}$ sehr wirksam zurükweist und nur um deswillen hier steht eben deshalb nicht urgiren ohnerachtet Moses wirklich die zweiten Tafeln selbst beschrieben zu haben scheint Exod 34, 27. 28. -


allenfalls daraus schließen daß sich Moses beim Herrn aufdekkt um sie zu

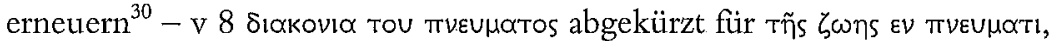

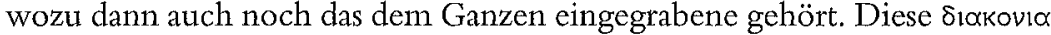

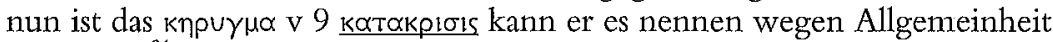
des Fluchs ${ }^{31}$ demohnerachtet aber - oder vielmehr deswegen darf man das

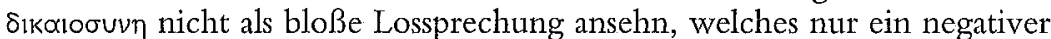
Begriff ist und auch das Leben nicht in sich schließt. Offenbar ist die $\delta \circ \xi \alpha$ in beiden Fällen nicht dieselbe denn er kann hier nur eine geistige meinen. Außer diesem Gegensaz scheint aber noch eine Steigerung intendirt. - v 10 ist rein parenthetisch denn 11 schließt sich auf das leichteste an $v 9$ an. Dies spricht schon hinreichend gegen die von Chrysostomus ausgehende vergleichende Erklärung ${ }^{32}$. Denn wenn es heißt die $\delta \circ \xi \alpha$ des alten ist gar nichts

26 Vgl. 2 Kor $2,15-17$.

27 Vgl. Röm 7,5-23.

28 Vgl. Gal 3,21.

292 Kor 3,2.

30 Vgl. Ex 34,34.

31 Vgl. Gal 3,10.

32 Vgl. Johannes Chrysostomus, In II epistolam ad Corinthios homilia 7,2. Danach bedeutet der Vers, die zugestandene Herrlichkeit des Alten Testaments sei im Vergleich mit derjenigen, die das Amt des Geistes habe, nicht für Herrlichkeit zu achten. 
gegen die neue: so müßte damit geschlossen und könnte die Vergleichung nicht noch fortgesetzt werden. Ohne Vergleichung nun kann es wol nur auf den alten Bund allein gehn so $\mathrm{da} \beta$ in $\cup \pi \varepsilon p \beta \alpha \lambda \lambda \circ \cup \sigma \alpha \alpha \delta \circ \xi \alpha$ seine ganze Herrlichkeit gesezt in oủ $\delta \varepsilon \delta \circ \xi \alpha \sigma \tau \alpha$ aber etwas ausgeschlossen wurde und

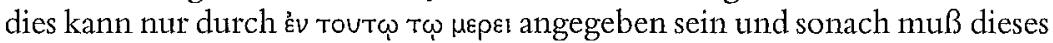

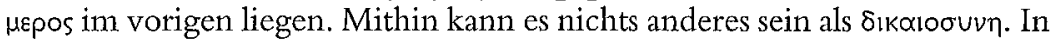
dieser Hinsicht ist es auch nicht verherrlicht und wenn wir auch alle seine

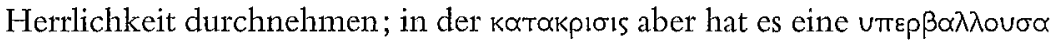
$\delta \circ \xi \alpha . \mathrm{v} 11$ elliptischer Saz mit für uns doppelt ausgelassenem verbo. Die Gesezgebung war nun doch mit anderer $\delta \circ \xi \alpha$ verbunden Paulus aber bleibt

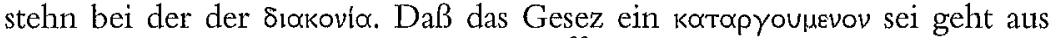

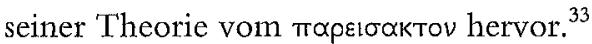

Segment 6, [Kapitel 3,] 12-18. weiter Gegensaz zwischen den An-

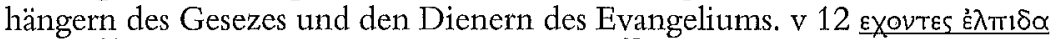

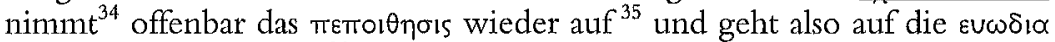

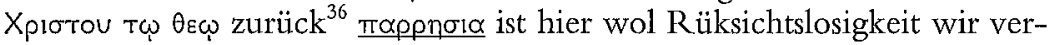
lassen uns auf die $\delta \circ \xi \alpha$ die uns mit ihren Wirkungen nicht im Stich läßt - v 13 $k \alpha i$ oủ $k \alpha \theta \dot{\alpha} \pi \varepsilon \rho$ fehlt ein verbum welches aus $x p \omega \mu \varepsilon \theta \alpha^{37}$ herauszunehmen ist,

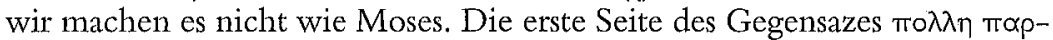
p $\sigma_{1} \alpha$ hernach noch einmal mit anderer óder weiterer Ausführung zu wicderholen ist ganz Paulinische Art. An eine Parenthese ist hier nicht zu denken. Auch nicht fehlt eigentlich ös nach Moses: Wir sind offen und nicht wie Moses anlegte. - трòs tò ù̀ giebt den [pag. 9] Schein einer Absicht.

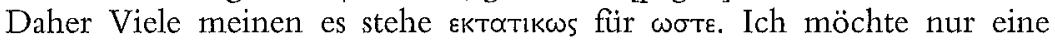

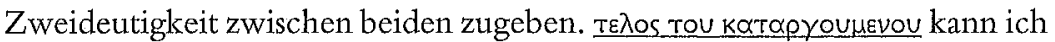

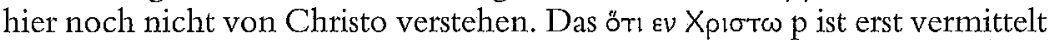
durch die $\pi \propto \lambda \alpha ı \alpha \delta ı \theta \eta \eta \eta \eta$ und also nur auf die Gegenwärtigen bezogen. ${ }^{38}$ To

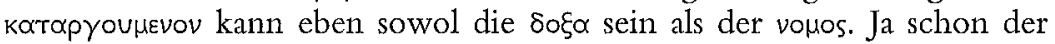
Umstand daß das leztere hernach noch ausdruiklich genannt wird spricht für

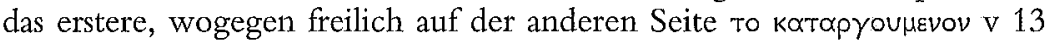
schon Gesez bedeutet. Allein seitdem ist ein anderer Zusammenhang an-

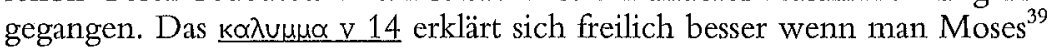
schon oben für Gesez nimt. Das Gesez hat seine Decke so daß sie das Ende des vorher endenden nämlichen Gesezes nicht sehn sondern sie sind stumpf-

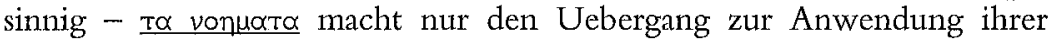
Denkungsweise. Bei dieser Wendung ist freilich tò $\alpha u ̛$ to k $\alpha \lambda u \mu \mu \alpha$ sonderbar

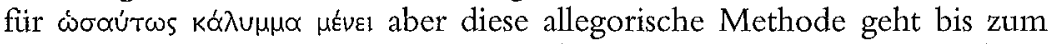

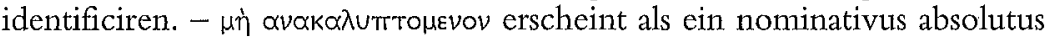
statt des Genitivs: indem sich ihnen nicht entdekt; das ist hier wol dadurch

\footnotetext{
33 Vgl. Gal 3,13.

34 Text: nicht

352 Kor 3,4 (vgl. oben).

362 Kor 2,15 .

372 Kor 3,12.

38 Vgl. 2 Kor 3,14.

39 Vgl. 2 Kor 3,7. 13.
} 


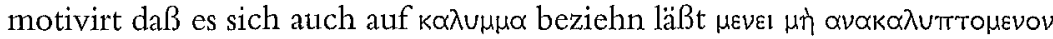



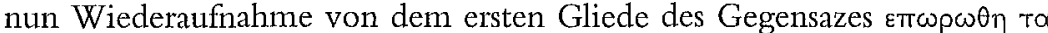

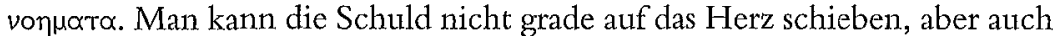

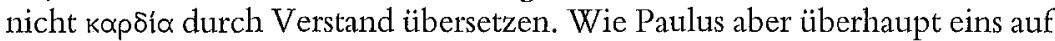
das andere zurïkführt so auch hier - v 16 Anspielung auf Moses zum Herm wieder hineingehn ohne Decke ${ }^{40}-\mathrm{v} 17$ scheint ganz ohne Zusammenhang zu stehn. In dem gewöhnlichen Sinn als Gegensaz zu dem knechtischen Zustand unter dem Gesez wäre es hier ganz fremd. Es geht aber auf die obige

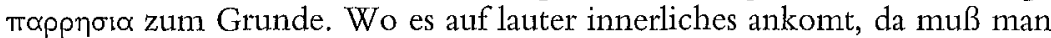
auch das Innere offen und rein herausgeben. Wie Moses $\gamma$ p $\mu \mu \alpha$ so Christus

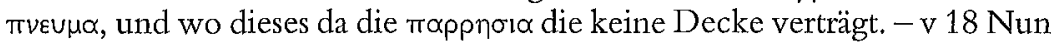
denkt man es wird kommen „,darum treiben wir unser Geschäft mit offenem Angesicht["]; aber dies wird in den Hintergrund gestellt und die Rede bleibt stehn bei der Vergleichung mit Moses. Wir strahlen zurük die $\delta \circ \xi \alpha$ kupıov.


werden, muß also mit $\mu \varepsilon т \alpha \mu о \rho ф о \cup \mu \varepsilon \theta \alpha$ verbunden werden und nun ist zweifelhaft wie beide Bestimmungen sich gegen einander verhalten. Das lezte ist die Spize[.] Bei uns ist diese Strahlung aber so wenig gleichmäßig wie bei Moses, aber nicht ein Wechsel von Erneuerung und Verschwinden des Glanzes sondern eine Spiegelung, welche auch schon von Anfang (seit v 9)

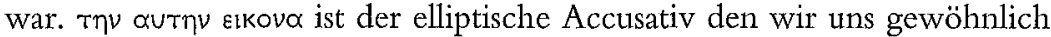

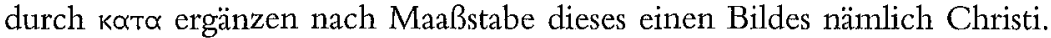
Denn wie ich früher erklärt tov autov троттоv das möchte wol keine Analogie

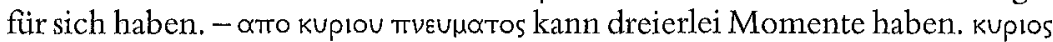
$\pi v \varepsilon v \mu \alpha$ und $\pi v \varepsilon v \mu \alpha$ kuprou kann man aus v 17 nehmen (кuplos $\pi v \varepsilon v \mu \alpha t o s$ hätte nichts fuir sich) $\pi v \varepsilon \cup \mu \alpha$ kuplou scheint das nächste und so kann auch das $\propto \pi т$

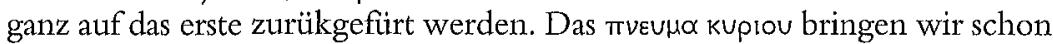
mit und von da aus werden wir aus einer Herrlichkeit in die andere verwandelt.

5.

Wie haben nun Schleiermachers Vorgänger den paulinischen Gegensatz gedeutet?

Für Origenes war 2 Kor 3,6-18 ein Schlüsseltext für die Hermeneutik: Gott ist Geist und kein sinnlich wahrnehmbares körperliches Wesen; tötender Buchstabe seien die körperlichen Wesen, Geist dagegen die intelligiblen oder Geistwesen. Der Geistigkeit Gottes entspreche ein Verständnis der Schrift, das über deren körperlichen, wahrnehmbaren, also buchstäblichen Sinn hinausgehe zum übersinnlichen, geistigen Verständnis. Solange man beim buchstäblichen Verständnis stehenbleibt, 
liegt noch die verhüllende Decke über dem Gesetz; die Geistigkeit und Heiligkeit des Gesetzes (vgl. Röm 7,12.14) erweist sich erst in dessen geistigem Sinn. Die Anschauung der Herrlichkeit des Herrn mit unverhülltem Angesicht ist also das über die Buchstäblichkeit hinausgehende allegorische Schriftverständnis. ${ }^{41}$ (An anderer Stelle kann Origenes die buchstäbliche Bedeutung der Schrift auch als die irdenen Gefäße bezeichnen, in denen sich nach 2 Kor 4,7 der herrliche Schatz verbirgt. ${ }^{42}$ ) Es ist die Erscheinung Jesu Christi, welche die Göttlichkeit und Geistigkeit der Schrift erweist und welche die diese bis dahin verhüllende Decke wegnimmt. ${ }^{43}$ Wenn die Juden meinten, nicht Jesus, sondern ein noch kommender politischer Herrscher sei der Messias, wenn die Gnostiker den Gott des Alten Testaments für inferior erklärten, wenn sich die einfältigen Christen über Gott törichte anthropomorphe Vorstellungen machten, so komme das alles daher, dass sie die Schrift weiter mpòs

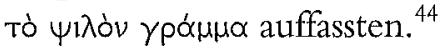

Die Exegeten der jüngeren antiochenischen Schule (vor und um 400) dagegen waren skeptisch bis ablehnend gegenüber dem Allegorisieren und bevorzugten die historische und typologische Schriftauslegung. Nach ihnen war mit dem tötenden Buchstaben nichts anderes gemeint als das den Sünder anklagende und richtende Gesetz als Inbegriff des Alten Testaments. ${ }^{45}$

Zu Beginn des pelagianischen Streites schrieb Augustin seine berühmte Abhandlung über Geist und Buchstaben; sie bestreitet die Meinung der Pelagianer, dass bereits das Gesetz die entscheidende Gnadengabe und Hilfe Gottes sei, die uns selig mache, indem sie dem Willen die richtige Richtung zeige. ${ }^{46}$ Das Gesetz allein bleibe vielmehr tötender Buchstabe; es mache die Sünde offenbar und verurteile sie, reize aber auch die Begehrlichkeit und vermehre die Sünde so noch. Auf sich

41 Vgl. Origenes, De principiis I, 1,2; Ders., Contra Celsum VI, 70; VII, 20.

42 Vgl. Origenes, De principiis IV 1,7.

43 Vgl. Origenes, De principiis IV 1,6. - Insofern trifft Gerhard Ebeling die Sache nicht ganz, wenn er schreibt, bei Origenes werde ,aus der heilsökonomischeschatologischen Wende eine ontologische und noologische Stufenfolge" (Art. „Geist und Buchstabe“, in: $\mathrm{RGG}^{3}$ 2, Tübingen 1958, 1290-1296, hier 1292).

44 Origenes, De principiis IV 2,1 $\mathrm{f}$.

45 Vgl. Johannes Chrysostomus, In II epistolam ad Corinthios homilia 6,2 f; Theodor von Mopsuestia, Homilia catechetica 11,8; Ders., In epistolam ad Romanos 7,6 (Karl Staab, Pauluskommentare aus der griechischen Kirche [NTA 15], Münster 1933, 126f).

46 Vgl. Augustin, De spiritu et littera II,4; XII,20; XIX,32. 
gestellt, habe der menschliche Wille nicht die Fähigkeit zur Erfïllung des Gesetzes. Erst durch den Geist Gottes, aus Gnade und nicht aufgrund eines vorhergehenden menschlichen Willensentschlusses, werde in den Menschen die göttliche Liebe eingegossen, durch die er das Gesetz erst seinem eigentlichen Sinne nach erfuille, nämlich aus Liebe und innerem Trieb, nicht als bloß äußerlicher Gehorsam gegen etwas Fremdes oder aus Furcht vor Strafe. ${ }^{47}$

Augustin hatte das origenistische Verständnis von 2 Kor 3,6 nach seiner eigenen Erzählung in Mailand bei Ambrosius kennengelernt; es hatte wesentlich dazu beigetragen, seine manichäischen Vorurteile gegen das Christentum zu beseitigen: Die Christen glaubten nicht wirklich an das, was die Bibel wörtlich verstanden an Anthropomorphismen über Gott aussagt. ${ }^{48}$ In der Schrift über Geist und Buchstaben weist er dieses Verständnis nicht zurück, sondern lässt es auch gelten. ${ }^{49}$ Trotzdem: Vom Buchstaben zum Geist wird die Schrift nicht durch die Allegorese, sondern durch die eingegossene Liebe und die gnadenhafte innere Verwandlung des Menschen zur Willenseinheit mit Gott.

6.

Martin Luther hat Augustins Schrift über den Geist und Buchstaben gründlich studiert, wohl in der ersten Zeit seiner Wittenberger biblischen Professur. Die Römerbriefvorlesung von 1515/16 bezieht sich ausdrücklich auf Augustins Schrift ${ }^{50}$ und zeigt eine selbständige Aneignung der augustinischen Unterscheidung von Buchstaben und Geist ${ }^{51}$. Luthers Frage ist es, wie der Buchstabe der Schrift vom Instrument des göttlichen

47 Vgl. Augustin, De spiritu et littera IV,6-V,8; XII,20; XIV,24-XXI,36; XXV,42.

48 Vgl. Augustin, Confessiones VI, IV,6.

49 Vgl. Augustin, De spiritu et littera IV,6-V,7.

50 Vgl. Adolf Hamel, Der junge Luther und Augustin, Bd. 1, Gïtersloh 1934, 912; Gerhard Ebeling, Die Anfänge von Luthers Hermeneutik, in: ZThK 48 (1951), 172-230, hier 186; Bernhard Lohse, Die Bedeutung Augustins für den jungen Luther, in: KuD 11 (1965), 116-135; Ders.: Zum Wittenberger Augustinismus, in: Kenneth Hagen (Hg.), Augustine, the Harvest, and Theology (1300-1650). Festschrift für Heiko Augustinus Oberman, Leiden, 89-109, hier 97-100; Hermann Dörries, Wort und Stunde, Bd. 3, Göttingen 1970, 92-95; Hans-Ulrich Delius, Augustin als Quelle Luthers, Berlin-Ost 1984, 7. 171-174. Lohse rechnet mit einer Bekanntschaft der Schrift de spiritu et littera bei Luther schon in dessen erster Psalmenvorlesung (1513-15).

51 Z.B. WA 56, 67. $336 \mathrm{f}$. 
Zorns zum erneuernden und freisprechenden Evangelium wird. Das geschieht eben nicht dadurch, dass man dem Buchstaben jeweils eine verschiedene sachliche Bedeutung zuweist, sondern dadurch, dass man dieselbe Aussage nicht von Mose, sondern von Christus her versteht, nicht als Anspruch und Forderung Gottes und Schuldspruch über den Sünder, sondern als Zusage der durch Christi Erlösungswerk erworbenen Gnade. Buchstabe und Geist werden also zu Gesetz und Evangelium. Demgegenüber verliert die von der Scholastik rezipierte origenistische Theorie, dass der Buchstabe durch den höheren Schriftsinn zum Geist wird (vgl. oben Abschnitt 5), an Bedeutung und wird schlieBlich abgelehnt. $^{52}$

In der Einleitung zur Winterpostille von 1522 schreibt Luther, Schrift im eigentlichen Sinne sei nur das Alte Testament. Das Evangelium sei seinem Wesen nach gar kein geschriebenes Wort, sondern eine mündlich verbreitete frohe Kunde, die die Schrift weitergibt, aber nun in neuer Weise, eben als Evangelium. Die Gefahr sei, dass man das Evangelium selbst zur Schrift, d.h. zum Gesetz macht. ${ }^{53}$ Hier haben wir also nicht

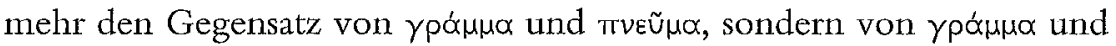
$\varepsilon \dot{v} \propto \gamma \gamma \gamma^{\dot{\varepsilon}} \lambda_{10}$. Das Evangelium, zu dem die Form des geschriebenen Buchstaben nicht passt, hebt diesen Buchstaben gleichwohl nicht auf, sondern bedarf seiner; es bezieht sich auf ihn, aktualisiert ihn und macht ihn zu etwas Neuem. Und dieses Neue ist eben das bleibende Ineinander von Geschriebenem und Mündlichem, Altem und Neuem.

In die zweite Auflage seiner Loci communes theologici von 1535 hat Philipp Melanchthon ein eigenes Kapitel „de spiritu et litera“ eingefügt. Hier stellt er Buchstaben und Geist auf verschiedenen Ebenen einander gegenüber: Bei Paulus bedeute beides einfach Altes und Neues Testament, damit zugleich aber auch das zwiefache Amt des göttlichen Wortes: das Amt, das anklagt und Tod und Verdammnis bringt, und das Amt, das den Geist bringt und Menschen freispricht und tröstet. "Geist" meine dabei den Heilige Geist selber und die Wirkungen des Geistes in den Herzen. Buchstabe und Geist seien damit dann auch zum einen die eigenen geistlosen Versuche des Menschen, das Gesetz zu erfüllen, und zum anderen die Gesetzeserfüllung aus den vom Geist mitgeteilten neuen

52 Vgl. Gerhard Ebeling, Evangelische Evangelienauslegung (FGLP 10, 1), München 1942, 278 f. 284. 287 f. 305. 353-355; Ders, , Die Anfänge (s. o. Anm. 50), 176. 216-230; Ders., Luther, 4. Aufl., Tübingen 1981, 106-108. 111-116. 120-131; Lohse, Zum Wittenberger Augustinismus (s.o. Anm. 50), 106 f. 
Motiven (ganz im Sinne Augustins, vgl. oben Abschnitt 5). Und schließlich stellten Buchstabe und Geist auch noch zwei Prinzipien dar, die es immer gebe und die immer miteinander bestehen müssten: Zucht und Regelgehorsam einerseits, Vertrauen auf die Verheißung andererseits. Disciplina, betont der Praeceptor Germaniae, brauche nämlich auch der Mensch unter dem Neuen Testament noch, nur dass er nicht glaube, durch sie selig zu werden, und fiducia hätten auch schon die Heiligen der alttestamentlichen Zeit gehabt, als sie auf Gottes Verheißung warteten. Falsch sei aber Origenes' Deutung des Geistes auf den allegorischen Sinn; auch der bleibe ja für sich doctrina, Gesetz und damit Buchstabe. ${ }^{54}$

\section{7.}

Die Reformatoren machten Buchstaben und Geist also zu Gesetz und Evangelium; wird beides nicht gehörig unterschieden, dann bleibt das Evangelium innerhalb der Logik von Verdienst, Lohn und Strafe befangen, wird selbst wieder zum Gesetz und verliert seine Kraft, Freiheit und Leben mitzuteilen. Zugleich grenzten sie sich scharf vom Geistverständnis der „Schwärmer“ ab: Diese beriefen sich auf innere Inspirationen und Offenbarungen kraft eines unmittelbaren Verhältnisses, in das sie zu Gott und seinem Geist gesetzt seien und das keiner äußeren vermittelnden Instrumente mehr bedürfe, durch das sie vielmehr selbst kompetent seien, Schrift und Predigt (als bloß äußerlichen Buchstaben) zu beurteilen. Luther und Melanchthon setzten dem entgegen, dass Gott seinen Geist und dessen Wirken gerade an das Äußere und Äußerliche

54 Vgl. Philipp Melanchthon, Loci communes theologici, 2. Aufl., Wittenberg 1535, cap. 17 (in: CR 21, 456-458). - Im August und September desselben Jahres hielt Luther eine Predigtreihe über 2 Kor 3. Luther legt hier dar, Buchstabe und Geist seien Gebot und Verheißung (und nicht wörtlicher Sinn und Allegorie, wie er noch im Studium gelernt habe). Das Gesetz sei eine gute Lehre, nur sei es nicht fähig, den Menschen zu verändern; das schaffe erst das gepredigte Wort des Evangeliums, an das Christus seinen Geist gebunden habe. Das Evangelium lehre, sich nicht auf eigene Werke zu verlassen, sondern das Werk Christi für sich anzunehmen; so tröste und erneuere es den Menschen. Wer das Evangelium wieder zum Gesetz mache, nehme ihın dagegen die Kraft. Die Lehrer der Werkheiligkeit seien die Schüler von Moses verdecktem Angesicht; vor Moses aufgedecktem Angesicht (der wahren Herrlichkeit des Gesetzes) müssten aber alle erschrecken, vor dieser habe menschlicher Selbstruhm keinen Bestand. Die so Erschreckten sollten zum lieblichen aufgedeckten Antlitz Christi fliehen und dort ihre Rettung finden (vgl. WA 41, 411-438). 
gebunden habe: an das aus der Schrift verkündigte Gesetz und Evangelium und an die Sakramente. ${ }^{55}$

Philipp Jakob Spener wollte anderthalb Jahrhunderte später der lutherischen Kirche, als deren rechtgläubigen Diener er sich selber sah, einen bescheidenen Fingerzeig für den Aufbruch in die verheißene bessere Zukunft geben. Entscheidend ist fuir ihn die Erkenntnis, dass Glaube, Religion und Theologie nicht (bloß) im Wissen, Lernen und Für-wahr-Halten bestünden; vor allem anderen seien sie Angelegenheiten der inneren Erfahrung und auch des praktischen, tätigen Lebens. Dementsprechend schreibt Spener, es gebe wohl Pfarrer, die aus der Schrift die rechte Lehre gefasst hätten, ihr auch beipflichteten und sie vortrügen, aber eben bloß so, wie man sonst eine Theorie erlerne, verstehe und weitergebe, ,allein dero buchstaben / ohne würckung deß Heiligen Geistes", während sie ,von dem wahren himmlischen liecht und leben deß glaubens gantz entfernet sind". Dabei möchte Spener nicht in den Donatismus verfallen und völlig leugnen, dass von solchen auch Gutes gewirkt werden könne; aber der Ertrag sei eben karg. Leider gelte, wer auf innere Erfahrung und Früchte des Glaubens im Leben dringe, immer gleich als heimlicher Papist, Weigelianer oder Quäker (also als ein mystischer Schwärmer und Sektierer, der sein inneres Licht über die rechtgläubige Lehre der Kirche setzt). ${ }^{56}$ - Spener ist weit davon entfernt, Geist und Rechtgläubigkeit oder gar Geist und Schrift gegeneinander auszuspielen; vielmehr empfiehlt er als Besserungsmittel für die Kirche, noch eifriger die Schrift zu studieren. ${ }^{57}$ Aber er unterscheidet zwischen dem bloßen Erkennen und Anerkennen dessen, was zwischen Gott Mensch wahr ist, und der eigentlichen Wirkung des Geistes, die den Menschen erneuert. Das Anerkennen der eigenen Rechtfertigung durch Christi Werk kann fuir Spener bloßer Buchstabe sein, trockene Theorie, genauso unwirksam wie nach Augustin das Gebot ohne den Geist (vgl.

55 Vgl. z.B. WA 18, 135-139 (Wider die himmlischen Propheten, 1525); Confessio Augustana 5 (BSLK, 58); WA 41, $412.417 \mathrm{f}$ (Predigten am 22.8, und 5.9. 1535); Articuli Smalcaldici III, 8,3-13 (BSLK, 453-456); ebenso auch Johannes Calvin, Institutio Christianae religionis, 4. Aufl. , Genf 1559, cap. I, 9 (CR 2, 69 72). Vgl. Reinhold Seeberg, Lehrbuch der Dogmengeschichte, Bd. 4,1, 2.-3. Aufl., Leipzig 1917, 308-314; Karl Holl, Gesammelte Aufsätze zur Kirchengeschichte, Bd. 1, 6. Aufl., Tübingen 1932, 425-438.

56 Philipp Jakob Spener, Pia desideria: Oder Hertzliches Verlangen / Nach Gottgefälliger besserung der wahren Evangelischen Kirchen, Frankfurt am Main 1676 (recte 1675), 14-17 (hg. v. Beate Köster, Gießen 2005, 32-34).

57 Vgl. a.a.O., 94-1.04 (108-118). 
oben Abschnitt 5). Spener trennt die Lehre von der Rechtfertigung von der inneren existentiellen Erfahrung, gerechtfertigt zu sein, und dem Leben aus der Rechtfertigung. Für Luther wäre das undenkbar gewesen. ${ }^{58}$

1799 erschien in Jena ein anonymes Buch über den „höchst wichtigen Paulinischen Gegensatz Buchstabe und Geist", das über die Exegese hinaus auch Grundsätzliches über das Wesen des Christentums zu sagen beanspruchte. Der Verfasser war Christian Friedrich Boehme, Lehrer und Pfarrer in Altenburg und Anhänger der Kantschen Philosophie. Das Wesen des Christentums, schreibt er, müsse aus dem Neuen Testament bestimmt werden, das aber ohne Vorentscheidungen durch einen Lehrbegriff oder eine Inspirationstheorie auszulegen sei. ${ }^{59}$

Mit Buchstaben und Geist meine Paulus zunächst Judentum und Christentum in ihrem Gegensatz gegeneinander ${ }^{60}$ und damit zugleich den wesentlichen Vorzug des Christentums gegenüber dem Judentum, kraft dessen es bestimmt sei, dieses abzulösen: Buchstabe bedeute Schrift und damit eine schriftlich beurkundete Religionsverfassung, eine Buchreligion; Geist hingegen stehe für eine Religionsverfassung, die nicht schriftlich beurkundet sei und deren Wesen in dem liege, was nicht wahrnehmbar und schriftlich zu fixieren sei. ${ }^{61}$ Zur Buchreligion gehöre es, dass das, was geschrieben steht, nicht aus Vernunftgründen kritisiert oder als Akkomodation an das damalige Verständnis relativiert werden könne und dass das Ethos zur bloßen Legalität anhand positiv festgesetzter Gebote werde. All das münde notwendig in eine theokratische Institution, die die Auslegung der Urkunde vorgebe, über die Rechtgläubigkeit wache und Zeremonien anordne. Eine derartig verfasste Religionsge-

58 Vgl. dazu auch Johannes Wallmann, Der Pietismus, Göttingen 2005, $28 \mathrm{f}$.

59 Vgl. [Christian Friedrich Boehme,] Neue Erklärung des höchst wichtigen Paulinischen Gegensatzes Buchstabe und Geist, Jena 1799, I-X. Bochme fuihrt weiter (X-XXVII) aus, die Inspirationstheorie beruhe auf mehreren Hypothesen: Gott existiere, Offenbarung sei möglich, sei wirklich und finde sich in der Bibel. Gegen das Letzte spreche, dass zu der Tugend und Gottseligkeit, auf die alles göttliche Handeln notwendig ziele, auch gehöre, nichts bloß aufgrund fremder Autorität ohne Prüfung durch die eigene Vernunft anzunehmen; das sei auch der Sinn von Röm 14,23.

60 Vgl. a.a.O., $18 \mathrm{f}$.

61 Vgl. a.a.O., 22-39. 
meinschaft könne sich aber nicht weiterentwickeln und hebe sich irgendwann selbst auf. ${ }^{62}$

Das Christentum dagegen ist nach Boehmes These

„eine, nicht schriftlich, sondern durch den Geist d.i. durch moralische Gesetzgebung und deren Vermögen, die sittlich-praktische Vernunft, begründete Religionsverfassung “63.

Leider habe es in der Gegenwart ganz den Charakter einer Buchreligion angenommen. ${ }^{64}$ Jesus und die Apostel aber wollten gar keine schriftliche Religionsurkunde schaffen, sie traten nicht für Glauben aufgrund fremder Autorität ein, sondern für eigenes Prüfen und für die Tugend statt Legalität anhand eines von außen gegebenen Gebots. Bei ihrem Lehren hätten sie sich an das damalige Verständnis akkomodiert und für die Zukunft die volle Einsicht verheißen. Den modernen Gegensatz von Vernunft und Offenbarung kenne das Neue Testament nicht; entscheidend sei in ihm immer die praktische Vernunft, die innere Haltung der Moralität. ${ }^{65}$

Eine nicht im Buchstaben, sondern im Geist beurkundete Religionsverfassung beruhe also auf der Vernunftwahrheit, nicht auf positiver Offenbarung und Autorität. Nur als solche könne eine Religionsverfassung auch allgemein werden und die Zeiten überdauern. ${ }^{66}-$ Buchstabe und Geist sind für Boehme also Chiffren für die (zum Beispiel auch von Kant geteilte) Vorstellung, dass die positive Religion allenfalls eine zeitbedingte Akkomodation an die noch nicht voll ausgebildete menschliche Vernunft sei; wenn der Mensch äußerer Autorität nicht mehr bedürfe, werde sie in die Vernunftreligion übergehen ${ }^{67}$.

62 Vgl. a.a.O., 43-71.

63 A.a.O., 232.

64 Vgl. a.a.O., 83-85.

65 Vgl. a.a.O., 87-154. 194-232. 248-271.

66 Vgl. a.a.O., 162-181. 310-314.

67 Vgl. Immanuel Kant, Die Religion innerhalb der Grenzen der bloßen Vernunft, 2. Aufl., Königsberg 1794, 167-183 (in: Ders, Akademie-Ausgabe, Bd. 6, Berlin 1914, 115-124); Ders., Der Streit der Facultäten, Königsberg 1798, 70115 (in: Ders., Akademie-Ausgabe, Bd. 7 [s.o. Anm. 3], 48-69). 
Fichte hat sich in der siebten seiner geschichtsphilosophischen Vorlesungen über die „Grundzüge des gegenwärtigen Zeitalters“ (1804/05) mit der Frage beschäftigt, wie das Christentum zu einer Buchreligion werden konnte. Das ursprüngliche, jesuanische und johanneische Christentum ist hier nicht wie bei Boehme (vgl. oben Abschnitt 8) die Religion der praktischen Vernunft, sondern eine Art Mystik, die schlichte und einfältige geistliche Erfahrung eines ewigen und unvermittelten Verhältnisses zum göttlichen Urgrund allen Seins. Diese ergeht sich nicht weiter in unfruchtbarem Räsonnement und ist gegen das Geschichtliche ganz gleichgültig; sie kennt nur die innere Evidenz und den praktischen Wahrheitsbeweis im Sinne von Joh 7,16 f. Es war Paulus, der Jude, der das Christentum nach dem Vorbild seiner Muttereligion verfälschte, indem er ihm die Vorstellung einpflanzte, Gott sei ein persönliches Wesen, mit dem man Verträge abschließe und das belohne oder bestrafe. An die Stelle der jüdischen Gesetzesobservanz trat bei Paulus eine andere Observanz, die er für heilsnotwendig erklärte: die Zustimmung zu dem Dogma, dass Jesus der Messias sei. So kam die Forderung einer materialen Rechtgläubigkeit ins Christentum, mit ihr Verwirrungen mit der Philosophie, Streitigkeiten, Spaltungen und ein autoritatives Lehramt. - Die Reformation lehnte Lehramt und die mündliche Tradition als Autoritäten ab, aber nur zugunsten des heiligen Buchs, das sie, um sich eine breite Basis zu schaffen, unter das Volk brachte; so machte sie das Christentum vollends zur Religion des geschriebenen Buches. Spätere Protestanten näherten sich dem Gnostizismus (d.h. sie wollten nur glauben, was sie eingesehen hatten) und forderten eine Auslegung nach der Vernunft. Obwohl sie einige paulinische Irrtümer wie die Satisfaktionslehre beseitigten, behielten sie doch den Grundirrtum bei, die Annahme eines persönlichen, nach Willensentschluss handelnden, belohnenden und bestrafenden Gottes. Allmählich verlor der Protestantismus fast den Charakter der positiven Religion. Eine Zukunft werde das Christentum nur haben, wenn es zum Urchristentum Jesu und Johannis zurïckkehre. ${ }^{68}$

Für den Gegensatz zwischen dem paulinischen und dem ursprünglichen Christentum nach Fichte hätte das Begriffspaar „Buchstabe und

68 Vgl. Johann Gottlieb Fichte, Die Grundzüge des gegenwärtigen Zeitalters, Berlin 1806, 210-226 (in: Ders., Akademie-Ausgabe, Bd. I/8, hg.v. Reinhard Lauth/ Hans Gliwitzky unter Mitwirkung v. Josef Becker/Erich Fuchs/Ives Radrizzani/ Peter K. Schneider, Stuttgart-Bad Cannstatt 1991, 269-275). 
Geist" gepasst, aber Fichte hat sich seiner enthalten (vielleicht wegen dessen paulinischen Ursprungs). Fichtes Auffassung, dass Paulus durch seine aus dem Judentum übernommenen Vorstellungen das ursprüngliche Evangelium Jesu verfälscht habe, fand Nachfolger, darunter Paul de Lagarde und manche Propheten einer völkischen Religion. ${ }^{69}$ Nach der moralischen Diskreditierung der völkischen Religiosität lebt das Schema mit umgekehrtem Vorzeichen weiter: Nun ist Jesus der fromme Rabbi und Paulus derjenige, der Jesu schlichtes Judentum zu einer synkretistischen Weltreligion mit griechisch-philosophischem Einschlag verformt hat. $^{70}$

\section{0.}

Was der junge Schleiermacher in den ,Reden' über den Buchstaben in der Religion sagt (vgl. oben Abschnitt 3), steht den "Schwärmern“ der Reformationszeit (vgl. oben Abschnitt 7) nahe: Auf die Schrift komme es wenig, auf die innere Beisterung umso mehr an. Man kann aber auch auf Plato verweisen: Lehren solle man nicht schriftlich weitergeben, denn das geschriebene Wort sei bloß ein schwaches Abbild der lebendigen Rede. ${ }^{71}$ - Boehmes Buch über Buchstaben und Geist (vgl. oben Abschnitt 8) hat Schleiermacher Anfang 1805 unbestellt erhalten, dann aber behalten. ${ }^{72}$ Weiter geäußert hat er sich nicht mehr dazu. - Fichtes Konstruktion über das Urchristentum, Paulus und die Reformation (vgl. oben Abschnitt 9) hat Schleiermacher in einer Rezension mit geradezu höhnischem Sarkasmus zurückgewiesen: Fichte schreibe Jesus so etwa das zu, was er sich

69 Vgl. Horst Stephan, Die Geschichte der evangelischen Theologie seit dem Deutschen Idealismus (Die Theologie im Abriß 9), Berlin 1938, 205-208; Emanuel Hirsch, Geschichte der neuern evangelischen Theologie im Zusammenhang mit den allgemeinen Bewegungen des europäischen Denkens, Bd. 4, Gütersloh 1952, 389 f; Günther Bornkamm, Paulus, Stuttgart 1969, 234-236; Klaus Scholder, Die Kirchen und das Dritte Reich, Bd. 1, Frankfurt a.M. 1977, 102-105. 703-705; Kurt Nowak, Evangelische Kirche und Weimarer Republik, Weimar 1981, 244-248.

70 Vgl. z. B. Geza Vermes, The Religion of Jesus the Jew, London 1993, 208-213; Rudolf Augstein, Paulus oder Jesus?, in: Der Spiegel 50 (1996), Nr. 23 (3.6.), 73-79; Gerd Lüdemann, Paulus, der Gründer des Christentums, Lüneburg 2001, 193-216. Vgl. auch Bornkamm (s.o. Anm. 69), 236-238.

71 Vgl. Phaedrus 276a; Epistola 2, 314bc; Epistola 7, 341b-e.

72 Vgl. Friedrich Daniel Enst Schleiermacher, Brief 1898 (14.1.1805) an Georg Andreas Reimer (in: Ders., Kritische Gesamtausgabe [s.o. Anm. 9], Bd. V/8, hg. v. Andreas Arndt/Simon Gerber, Berlin/New York 2008, 92 f). 
als die Religion des von ihm postulierten rein vernünftigen „Normalvolkes" ausgedacht habe (dessen Zusammentreffen mit den vernunftlosen „erdgeborenen Wilden“ den Anfang der Geschichte bedeute). Tatsächlich stehe Jesus nicht weniger als Paulus auf dem Boden des Judentums; bei ihm finde sich - selbst in der johanneischen Darstellung - ïberall das, was Fichte als paulinisch-jüdisch verwerfe (zum Beispiel der geforderte Glaube an Jesus als Messias und die Versöhnungslehre). Paulus wiederum, dem man freilich vorwerfen könne, dass er Fichtes Mythos vom Normalvolk nicht gekannt habe, sei gerade dagegen aufgetreten, Christentum. und menschliches Räsonnement miteinander zu vermengen; als Apostel der Heiden habe er das Christentum auch nicht als neuen Sinaibund dargestellt, es vielmehr an die an Abraham ergangenen älteren VerheiBungen angeknüpft. Fichtes Deutung der Reformation lohne der Entgegnung gar nicht. ${ }^{73}$ Fichte wiederum meinte, er kenne die Waffen der Theologen nur zu gut, sie seien auf ihrem Gebiet leider unïberwindlich. $^{74}$

Als Einfuihrung in die Technik der Textauslegung (besonders des Neuen Testaments) hat Schleiermacher seit 1805 Vorlesungen zur Hermeneutik gehalten. In einem der Kollegien erwähnt er auch das Gegensatzpaar „Geist und Buchstabe", allerdings nicht im Sinne der hermeneutischen Theorie des Origenes (vgl. oben Abschnitt 6):

„Viele unmittelbare Gegensäze bietet es dar wegen der eigenthümlichen Art der hebräischen Composition. Aber auf die entfernten ist wenig Verlaß wegen ungenauen Verfahrens der Schriftsteller. Auch sind die HauptGegensäze Geist und Fleisch, Geist und Buchstabe Licht und Finsterniß Himmel und Erde $p$ so groß und viel umfassend daß sie wieder auf mancherlei Weise bestimmbar sind." 75

„Geist und Buchstabe“ ist für Schleiermacher also ein Beispiel neben anderen für eine typische Eigenart der neutestamentlichen Diktion,

73 Vgl. [Friedrich Daniel Ernst Schleiermacher,] Rezension zu Johann Gottlieb Fichte, Die Grundzüge des gegenwärtigen Zeitalters, Berlin 1806, in: Jenaische Allgemeine Literatur-Zeitung 4 (1807), Bd. 1, Nr. 18-20 (21.-23.1.), 137-160, hier $156 \mathrm{f}$ (in: Ders., Kritische Gesamtausgabe, Bd. I/5 [s.o. Anm. 16], 145147). Vgl. zum Mythos vom Normalvolk Fichte, Die Grundzüge (s. o. Anm. 68), 288-293 (in: Ders., Akademie-Ausgabe, Bd. I/8 [s.o. Anm. 68], 298-300).

74 Vgl. Fichte, Die Grundzüge (s. o. Anm. 68), 225 f (in: Ders., Akademie-Ausgabe, Bd. I/8 [s.o. Anm. 68], 275).

75 Friedrich Daniel Ernst Schleiermacher, Hermeneutik 1805, 23. Stunde (in: Ders., Kritische Gesamtausgabe [s.o. Anm. 9], Bd. II/4, hg.v. Wolfgang Virmond unter Mitwirkung von Hermann Patsch, Berlin/Boston 2012, 49). 
nämlich die Erörterung anhand von einander entgegengesetzten $\mathrm{Be}-$ griffen. Schleiermacher führt sie zurïck auf die hebräische Vorliebe, Gedanken als antithetischen Parallelismus membrorum zu formulieren. Dazu gehört dann aber auch, dass diese Begriffe inhaltlich nicht exakt bestimmt sind, sondern ihre Bedeutung an der jeweiligen Stelle immer dem weiteren Zusammenhang zu entnehmen ist.

Damit kommen wir auf Schleiermachers eigene Ausarbeitung zu 2 Kor 3 zurück (vgl. oben Abschnitt 4). Hier deutet Schleiermacher den „HauptGegensaz" „Buchstabe und Geist" so wie seine Vorgänger auf den Unterschied des Alten Testaments (oder Judentums) zum Neuen Testament, und ähnlich wie die Antiochener, Augustin und die Reformatoren (vgl. oben Abschnitt 5 und 6) versteht er unter dem Buchstaben nicht den wörtlichen Schriftsinn oder die Schriftlichkeit und Positivität des Alten Testaments als Religionsverfassung, sondern das Gesetz. Er zieht dafuir zur Vertiefung noch Stellen aus Röm 7 und Gal 3 mit heran.

In der Einordnung des Gesetzes unterscheidet sich Schleiermacher dann aber charakteristisch von den Vorgenannten: Das Gesetz ist nicht die Offenbarung des Gotteswillens, die den Sünder überführt und richtet. Das tötende Wesen des Buchstaben besteht tatsächlich eher in dessen Unzulänglichkeit: Das Gesetz ist zwar geistig, indem es aus der Erkenntnis des Guten kommt, aber in seinen Verheißungen appelliert es an die diesseitig-sinnlichen Wünsche des Menschen und reizt so selbst zur Sinnlichkeit, es ist gegenüber der Abrahamsverheißung sekundär und unfähig, Leben zu bringen; statt dessen bringt es den Fluch. Wenn die

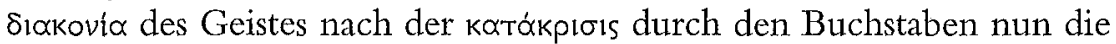

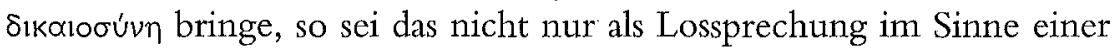
bloßen Negierung des vorigen Verdammungsurteils gemeint, sondern als positiver Inhalt, der das Leben in der Gerechtigkeit mit einschließt. In diesem Sinne hat Schleiermacher sich auch andern Orts von der besonders von Melanchthon vertretenen forensisch-imputativen Rechtfertigungslehre abgegrenzt. ${ }^{76}$

76 Vgl. Friedrich Daniel Ernst Schleiermacher, Kirchengeschichte 1821/22, 94.97. Stunde (in: Ders., Kritische Gesamtausgabe [s.o. Anm. 9], Bd. II/6, hg. v. Simon Gerber, Berlin/New York 2006, 637. 648 f); Ders., Kollektaneen 918; 935 (in: Ders., Kritische Gesamtausgabe, Bd. II/6, 375. 380); Ders., Predigt 154 
Hermann Peiter hat auf eine Geistesverwandtschaft zwischen Schleiermacher und dem Antinomer Johann Agricola hingewiesen, die Schleiermacher in seinen Vorlesungen zur Kirchengeschichte selbst auch offen ausspricht: Die christliche Gemeinde braucht das alttestamentliche Gesetz als Hinführung zu Christus nicht. ${ }^{77}$ Auch sonst hat Schleiermacher (ohne die Wurzeln des Christentums im Judentum zu leugnen) das Christentum von der Religion des Alten Testaments strikt geschieden. ${ }^{78}$ Ebenso auch hier: Das Gesetz steht in keinem speziellen Zusammenhang

(18.7.1830) iiber Ga1 2,19-21 (in: Ders., Predigten in Bezug auf die Feier [s.o. Anm. 19], 70-73; in: Ders., Sämmtliche Werke, Bd. II/2 [s.o. Anm. 19], 658 660); Ders., Der christliche Glaube nach den Grundsäzen der evangelischen Kirche im Zusammenhange dargestellt, 2. Aufl., Bd. 2, Berlin 1831, \$109 (in: Ders., Kritische Gesamtausgabe [s.o. Anm. 9], Bd. I/13, 2, hg.v. Rolf Schäfer, Berlin/New York 2003, 191-202). Vgl. demgegenüber etwa Rudolf Bultmann, Der zweite Brief an die Korinther, KEK Sonderband, Göttingen, 1976, 85 f. 77 Vgl. Hermann Peiter, Schleiermacher und der Antinomismus, in: Kurt-Victor Selge (Hg.), Internationaler Schleiermacher-Kongreß Berlin 1984, Bd. 2 (SchlA 1,2), Berlin-West/New York 1985, 1017-1029; vg1. Schleiermacher, Kirchengeschichte 1821/22, 96.-97. Stunde (in: Ders., Kritische Gesamtausgabe, Bd. II/6 [s.o. Anm. 76], 646 f); Ders., Kollektaneum 957 (in: Ders., Kritische Gesamtausgabe, Bd. II/6, 384).

78 Vgl. [Schleiermacher,] Über die Religion ${ }^{1}$ (s. o. Anm. 9), 286-290' (in: Ders., Kritische Gesamtausgabe, Bd. I/2 [s.o. Anm. 9], 314-316); Ders., Kirchengeschichte 1821/22, 2. Stunde (in: Ders., Kritische Gesamtausgabe, Bd, II/6 [s.o. Anm. 76], 22. 473); Ders., Kirchengeschichte 1825/26 (in: Ders., Kritische Gesamtausgabe, Bd. II/6, 673); Ders., Christliche Sitte 1826/27 (in: Ders., Sämmtliche Werke, Bd. I/12, hg.v. Ludwig Jonas, Berlin 1843, 292 f); Ders., Der christliche Glaube nach den Grundsäzen der evangelischen Kirche im Zusammenhange dargestellt, 2. Aufl., Bd. 1, Berlin 1830, $\$ 12$ (in: Ders., Kritische Gesamtausgabe [s.o. Anm. 9], Bd. I/13, 1, hg.v. Rolf Schäfer, Berlin/New York 2003, 102-106); Bd. 2 (s. o. Anm. 76), $\$ 93,3$ f; 132; 156 (in: ders., Kritische Gesamtausgabe, Bd. I/13, 2 [s.o. Anm. 76] , 45-51.337-341. 450-455); Ders., Theologische Enzyklopädie 1831/32, \$46 (hg.v. Walter Sachs [SchlA 4], BerlinWest/New York 1987, 53). - Vgl. Hans-Walter Schütte, Christiicher Glaube und Altes Testament bei Friedrich Schleiermacher, in: Dietrich Rössler/Gottfried Voigt/Friedrich Wintzer (Hg.), Fides et communicatio. Festschrift für Martin Doerne zum 70. Geburtstag, Göttingen 1970, 291-310; Wilhelm Gräb, Humanität und Christentumsgeschichte (GTA 14), Göttingen 1980, 111-118. 201 f; Klaus Beckmann, Die fremde Wurzel (FKDG 85), Göttingen 2002, bes. 31-90; Simon Gerber, Christentum und Judentum in Schleiermachers Vorlesungen über die Kirchengeschichte, in: Roderich Barth/Ulrich Barth/ Claus-Dieter Osthövener (Hg.), Christentum und Judentum. Akten des internationalen Kongresses der Schleiermacher-Gesellschaft in Halle, März 2009 (SchlA 24), Berlin/Boston 2012, 385-401. 
mit dem Neuen Testament. - Augustin hatte, angeregt vom Stichwort "ministri novi testamenti“ (2 Kor 3,6), die Verbindung gezogen zur alttestamentlichen Verheißung eines neuen Bundes (Jer 31 [38

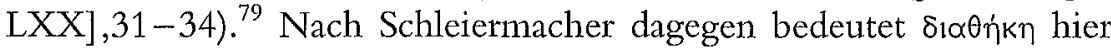
nicht den Bund, sondern die göttliche Anordnung, also eine zweite göttliche dispositio, etwas gegenüber dem alten Dienst des Buchstaben und dessen Regeln grundsätzlich anderes. Von Paulus wird die Geschichte über die Gesetzestafeln des Mose hier im Grunde nur angeführt, weil sie ihm zur Illustration dienen kann und weil sie als heilige Schrift eine anerkannte Autorität darstellt.

Es gibt in Schleiermachers Ausarbeitung noch bemerkenswerte

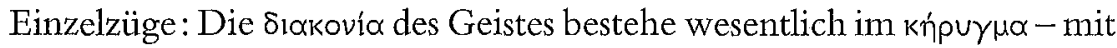
dieser Feststellung erinnert Schleiermacher schon an einen Typus der Theologie im 20. Jahrhundert, der dann über Schleiermachers Leistungen sehr absprechend urteilte. Zu 2 Kor 3,10 meint Schleiermacher (nicht nur gegen Chrysostomus, den er hier nennt und den er als einen , native speaker" neben anderen griechischen Kirchenvätern bei der Exegese zu konsulticren pflegt, sondern gegen praktisch alle anderen), hier werde

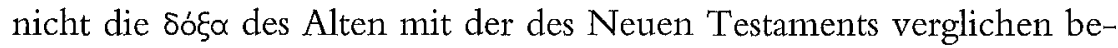
ziehungsweise die $\delta o ́ \xi \alpha$, die der Dienst des Buchstaben hat, mit derjenigen

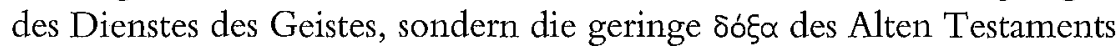

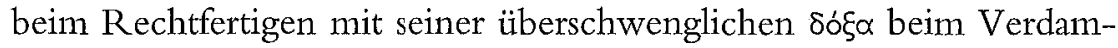
men.

Die Ausführung über die Gesetzestafeln und die Decke sind für Schleiermacher insgesamt beispielhaft für den paulinischen Umgang mit der Schrift: Paulus kann die Heilsgeschichte mit der größten Souveränität zur Allegorie für das machen, was er̀ verdeutlichen und untermauern will, bis dahin, dass er Mose mit dem Gesetz identisch setzt und die Decke, die damals über Moses Angesicht lag, mit der Decke, die den jüdischen Zeitgenossen einstweilen noch das Verständnis verdeckt. Dabei lässt das Allegorisieren aber das Faktum bestehen und erklärt es nicht zu einem bloßen Symbol. ${ }^{80}$ - Schließlich wird deutlich, dass Exegese für Schleiermacher vor allem philologisch-kritische Arbeit und Rekonstruktion der Beziehungen und Zusammenhänge innerhalb eines Textes ist. So müht er sich mit der philologisch schwierigen Frage, wie das $\mu \grave{\eta} \alpha^{\alpha} v \alpha \kappa \alpha-$

79 Vgl. Augustin: De spitritu et littera XIX,33-XXV,42.

80 Es handelt sich also tatsächlich eher um eine Typologie als um eine Allegorese; vgl. Leonhard Goppelt, Art. „тứtos $\mathrm{kT} \lambda$ “, in: ThWNT 8, Stuttgart 1969, $246-$ 260 , hier $251-257$. 


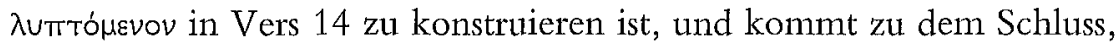
dass es sich nicht als Attribut oder Participium coniunctum auf кó $\lambda \cup \mu \mu \alpha$ bezieht, sondern ein Nominativus absolutus ist.

\section{2.}

Den exegetischen Ertrag hat Schleiermacher noch fruchtbar gemacht fuir seine Predigtreihe zum Jubiläum der Confessio Augustana, die große Bestandsaufnahme und Wegweisung für die Kirche der Reformation. Hier warnt er nicht nur vor geisttötender Buchstäblichkeit (vgl. oben Abschnitt 3). Er macht sich auch an eine aktualisierenden Vergegenwärtigung der reformatorischen Rechtfertigungslehre und kommt dabei auch zur paulinischen Lehre vom Gesetz: Ausgehend von dem auch in der Ausarbeitung zu 2 Kor 3 reflektierten Paradox, dass das Gesetz nicht lebendig machen könne (Gal 3,21) und doch Geist sei (Röm 7,14), führt Schleiermacher aus, ein Gesetz komme aus dem innersten geistigen Leben dessen, der es gebe, und sei insofern Geist und Leben; bei denen, denen es unter Verheißung von Lohn und Androhung von Strafe auferlegt sei, werde es aber zum äußerlichen, fremden Buchstaben, und seine Erfuillung sei dann ein totes Werk (Hebr 6,1). Leben und Gerechtigkeit kämen erst, wenn das, was das Gesetz fordere, von innen heraus und aus eigenem Antrieb ohne Vorschrift von außen getan werde. Auch das alttestamentliche Gesetz sei nun ein solcher äußerer Buchstabe : Es rechne selbst nicht damit, aus innerem Antrieb befolgt zu werden, setze vielmehr iiberall Unlust an seiner Erfüllung voraus, denn es ergehe sich in einer verwirrenden Fülle von kasuistischen Einzelvorschriften, statt das eine innerlich einzuprägen, wodurch alles dem Geist nach zusammenhängt. Ein solches Gesetz habe kein Leben, teile auch kein Leben mit und mache nicht gerecht. Und dasselbe wäre der Fall, wollte man der Gemeinde buchstäbliche Rechtgläubigkeit als ein äußerliches Gesetz auferlegen. ${ }^{81}$

81 Vgl. Friedrich Daniel Ernst Schleiermacher: Predigt 153 (4.7.1830) über Gal 2,16-18 (in: Ders., Predigten in Bezug auf die Feier [s.o. Anm. 19], 44-47. 57; in: Ders., Sämmtliche Werke, Bd. II/2 [s.o. Anm. 19], 641-643. 650). Vgl. zur Ohnmacht des bloßen äußeren Gesetzes als ,,todter Buchstabe“, der der Belebung durch den Geist des Vertrauens und der Liebe bediirfe, Ders., Zur Öffentlichen Sitzung der Akademie der Wissenachaften am 3. August 1826 (in: Ders., Kritische Gesamtausgabe [s.o. Anm. 9], Bd. I/11, hg.v. Martin Rössler unter Mitwirkung v. Lars Emersleben, Berlin/New York 2002, 520). Als politischer Prediger kann Schleiermacher in diesem Sinne Geist und Buchstaben 
In einer anderen Predigt dieser Reihe heißt es unter Anlehnung an 2 Kor 3, die evangelische Predigt dürfe nicht Gottes Eifer und Zorn verkünden. Das Amt, das durch den Buchstaben tötet und die Verdammnis predigt, habe nur eine vergängliche, unechte Klarheit und könne nicht Grundlage der Seligkeit werden. Das evangelische Amt sei das Amt des Neuen Testaments, in dem sich die Klarheit des Herrn spiegelt, weil es Geist, Liebe und Frieden bringt.

,Jezt ist die Zeit die Menschen aufzufordern, nicht daß sie sich vor dem Zorne Gottes flïchten sollen in den Schooß des Sohnes, sondern nur daß sie die Augen öffnen mögen, um in Christo die Herrlichkeit des eingebornen Sohnes vom Vater [Joh 1,14], und also im Sohne den Vater zu schauen [Joh 14,9], und von dem Sohne die Macht zu empfangen, daß sie Gottes Kinder werden [Joh 1,12]." ${ }^{\prime 82}$

Hier sehen wir also abermals Schleiermachers antinomistisches Verständnis der paulinischen Rechtfertigungslehre eingekleidet in den Gegensatz von Buchstaben und Geist und Altem und Neuem Testament: Der Buchstabe bleibt nicht wie bei den Reformatoren als usus elenchticus legis notwendig, um dem in der Spannung von iustus und peccator stehenden Gläubigen immer wieder den Weg vom selbstgerechten oder verzweifelnden alten Adam zu Christus zu weisen. Der Buchstabe, die Furcht vor dem strafenden Gesetz und dem Zorn Gottes, ist ein Missverstand, der vergeht, wenn im Geist die unvergängliche Herrlichkeit des eingeborenen Sohnes offenbar wird. ${ }^{83}$

unterscheiden, so dass etwa Ludwig Graf Yorck von Wartenburg und andere tapfere Heerfuihrer mit ihrem Abfall von Napoleon den Buchstaben der königlichen Befehle verletzt hätten, damit aber dem Geist des Königs umso besser gehorcht; vgl. Schleiermachers Predigten vom 15. Januar 1809 und vom 28. März 1813 (in: Ders., Kritische Gesamtausgabe, hg. von Günter Meckenstock u.a., Bd. III/4, hg. von Patrick Weiland unter Mitwirkung von Simon Paschen, Berlin/Boston 2011, 3-15, hier: 11; 563-577, hier: 564); vgl. dazu auch den Beitrag von Arnulf von Scheliha in diesem Band.

82 Friedrich Daniel Ernst Schleiermacher: Predigt 159 (24.10.1830) ïber 2 Kor $5,17 \mathrm{f}$ (in: Ders., Predigten in Bezug auf die Feier [s.o. Anm. 19], 189; in: Ders. , Sämmtliche Werke, Bd. II/2 [s.o. Anm. 19], 737 f).

83 Vgl. dazu auch Emanuel Hirsch, Fichtes, Schleiermachers und Hegels Verhältnis zur Reformation, Göttingen 1930, 39-46; Hans-Walter Schïtte, Die Ausscheidung der Lehre vom Zorn Gottes in der Theologie Schleiermachers und Ritschls, in: NZSTh 10 (1968), 387-397. 